\title{
Editorial
}

\section{Timişoara Medical Journal: A New Beginning}

\section{Octavian Crețu ${ }^{1,2}$}

\author{
I "Victor Babes" University of Medicine and Pharmacy, 30004I Timișoara, Romania \\ ${ }^{2}$ Municipal Clinical Emergency Hospital of Timișoara, 300254 Timișoara, Romania \\ Submitted: 5 November 2020; Accepted: 5 November 2020; Published: 25 November 2020
}

How to cite: Crețu, O. Timişoara Medical Journal: A New Beginning. Timisoara Med. 2020, 2020(I), II; doi:I0.35995/tmj20200IOII.

Timişoara Medical Journal (TMJ) is an international open-access, peer-reviewed journal of paramount importance in relation to the scientific and medical activity of the "Victor Babeș" University of Medicine and Pharmacy, Timişoara. After some years in which the activity of our journal ceased, with new forces and with a refreshed editorial board, $T M J$ is experiencing a new beginning with more ambitious goals. TMJ will continue to publish original research pertaining to the medical field, the dental medicine field, as well as the pharmaceutical field. Our hope is to offer a platform for both scientists across Romania and peers around the globe to publish their most remarkable findings. In this issue, we look forward to several innovative and exciting articles.

It is with gratefulness and confidence that I address this letter to you, our readers. I am grateful for being granted such an honor as that of occupying the position of Editor in Chief of this journal, and I am confident in the direction that we have planned for TMJ. I say "we" because no man alone can achieve great results, without the support of a group of highly regarded and talented peers, and such is the case of those that I am proud to call my editorial team. I truly believe that, with their support, the challenge represented by the broad medical sphere in which TMJ aims to publish will not be too great, and that international recognition and indexing will soon follow.

In these troubled times, it may seem redundant to engage in scientific endeavors, and present conditions around the globe might even make it difficult for some of us to have access to everything we need. I encourage each and every one of our readers to try to overcome these obstacles and prevail in their scientific research at a time in which there is an acute necessity for international collaboration and novel scientific discoveries.

It may be that the importance of our collective work as scientists around the globe has never been more evident than in these moments. We find ourselves in the midst of a global pandemic, fighting an invisible enemy that has impacted the lives of many of our patients, across all medical specialties. We cannot be certain of the outcome, but we know for a fact that we will have to aid all of our patients, both in overcoming this disease and in the long-term implications it could have for them. 
With these problems in mind, the need for change in regard to how we research, write and publish our work becomes evident. Our journal wishes to offer a platform that will aid in this process, its revival involving a team of young scientists defined by excellence, whose expertise and dedication to qualitative scientific research is a statement of their value to the scientific world, who also practice medicine on a daily basis, having intimate knowledge of their patients' struggles and needs, and who have reached impressive heights in their academic careers. Furthermore, we have added a significant number of reviewers to our team, in order to decrease the amount of time our authors have to wait in order to receive a response or a review. The reviewer selection process ensures that each reviewer is allotted manuscripts within his/her field of expertise and that they have proficient knowledge of the English language. Last but not least, TMJ is published using the Journal Articles Management System (JAMS) of one of the most prestigious publishing houses: the Swiss-based Multidisciplinary Digital Publishing Institute (MDPI).

We look forward to receiving your best work, be it in the form of original research articles, case reports, review articles or meta-analyses.

I am left only to thank my co-editors, the members comprising our editorial board, our reviewers, and the authors for their tremendous help in preparing this inaugural issue.

Funding: This research received no external funding.

Conflicts of Interest: The author declares no conflicts of interest.

(C) 2020 Copyright by the author. Licensed as an open access article using a CC BY 4.0 license.

(c) (i) 